\title{
ANALISIS LOAN TO DEPOSIT RATIO (LDR) DAN \\ CAPITAL ADEQUANCY RATIO (CAR) TERHADAP RENTABILITAS PADA PT. BANK TABUNGAN NEGARA (PERSERO) Tbk.
}

\author{
Yuslinda Nasution \\ n.yuslinda@yahoo.com \\ Jurusan Manajemen, Fakultas Ekonomi, Universitas Satya Negara Indonesia \\ Jalan Arteri Pondok Indah No.11 Jakarta Selatan
}

\begin{abstract}
This study aims to identify, analyze and be able to explain financial ratios, especially the level of liquidity that is calculated by using the ratio of loan to deposit ratio (LDR), calculating the solvency level by using the ratio of Capital Adequacy Ratio (CAR), and calculate profitability by using the ratio Retun On Assets (ROA), Return On Investment (ROI) and Net Interest Margin (NIM) In PT Bank Tabungan Negara (Persero) Tbk, which is one of the State Owned Enterprises in the field of banking services primarily in credit financing.To obtain the necessary data, the authors use data collection techniques, the type of data used in the form of primary data and secondary data.Based on the results of data processing by the author, it is known that there are three conclusions. The First. of the results of the liquidity ratio LDR decline in 2014 due to an increase of 1.66\% higher than the savings credit, and an increase back in 2015 of $3.52 \%$ for loans greater than the savings. Second, the results of the solvency ratio increased in 2014 compared to 2013 of $2.66 \%$ is due to an increase of capital by the end of 2013. And a decline back in 2015 of $2.07 \%$ is due to the decline in capital activities over the previous year. Third, the results of Profitability ratios using ROA calculation decreased by $0.08 \%$ in 2014 and decreased by $0.09 \%$ return this happens because the increase in net income is followed by an increase in the number of significant assets annually. While using the ROE also decreased by $0.75 \%$ in 2014 and decreased by $0.12 \%$ return is due to the growth of the share capital. And calculations using the NIM in 2014 increased by $0.07 \%$ due to significant asset growth, but a decline back in 2015 by $0.29 \%$ due to an increase in interest rates as a result of the BI rate.Can be seen from the calculation of financial ratios and earnings at PT Bank Tabungan Negara (Persero) Tbk showed good conditions and positive, although LDR exceed the provisions of Bank Indonesia, is because BTN is a bank loan portfolio for the long term.
\end{abstract}

Keywords : Loan to Deposit Ratio (LDR), Capital Adequacy Ratio (CAR), Rentabilitas

\section{PENDAHULUAN}

Bank sebagai lembaga keuangan yang menghimpun dana dari masyarakat dalam bentuk simpanan dan menyalurkan kembali dananya dalam bentuk kredit. Bank dapat dikatakan baik jika bank mampu menjaga tingkat likuiditasnya. Maksudnya pada posisi ini bank dituntut untuk menyalurkan kredit kepada masyarakat dari dana pihak ketiga (simpanan) 
yang ada, dan disisi lain bank harus memenuhi keinginan deposan yang akan menarik dananya sewaktu-waktu yang telah digunakan untuk memberikan kredit sehingga pada posisi seperti ini bank dituntut untuk tetap menjaga stabilitas likuiditasnya.

Modal merupakan faktor penting dalam upaya mengembangkan usaha. Jika bank memiliki modal yang rendah, bank akan mengalami insolvent (kewajiban melebihi aset yang dimiliki) bila terjadi kredit macet. Sehingga akan menurunkan kredibilitas bank, sehingga memicu terjadinya rush, yaitu nasabah secara serentak menarik dananya. Jadi untuk menanggulangi aktiva yang berisiko bank diwajibkan memiliki cadangan modal sesuai dengan ketetapan Bank Indonesia

Capital Adequancy Ratio (CAR) yang tinggi dapat dicapai melalui rentabilitas yang berasal dari laba. Sedangkan rentabilitas yang tinggi karena pendapatan bunga yang diperoleh dari kredit bank yang juga meningkat. Perumusan masalah dalam penelitian ini adalah:

a. Apakah Loan to Deposit Ratio (LDR) dapat mempengaruhi tingkat Rentabilitas pada PT Bank Tabungan Negara (Persero) Tbk?

b. Apakah Capital Adequancy Ratio (CAR) dapat mempengaruhi tingkat Rentabilitas pada PT Bank Tabungan Negara (Persero) Tbk?

c. Apakah Loan to DepositRatio (LDR) dan Capital Adequancy Ratio (CAR) secara bersamasama dapat mempengaruhi tingkat Rentabilitas pada PT Bank Tabungan Negara (Persero) Tbk?

\section{KERANGKA PEMIKIRAN TEORITIS}

Pengertian Bank menurut Undang-Undang RI Nomor 10 Tanggal 10 November 1998 adalah "badan usaha yang menghimpun dana dari masyarakat dalam bentuk simpanan dan menyalurkannya kembali dalam bentuk kredit, dan atau bentuk-bentuk lainnya dalam rangka meningkatkan taraf hidup rakyat banyak".

“ Loan to Deposit Ratio (LDR) adalah perbandingan antara seluruh jumlah kredit yang diberikan bank dengan dana yang diterima bank", (Dendawijaya,2003).

"Capital Adequancy Ratio (CAR) adalah rasio kinerja bank untuk menunjang aktiva mengandung atau menghasilkan risiko misalnya kredit yang diberikan", (Lukman Dendawijaya,2000:121).

"Rentabilitas adalah kemampuan suatu bank untuk menghasilkan laba selama periode tertentu dinyatakan dengan persentase", (Hasibuan,2006:100).

Menurut Hanafi (2007:159), "Return On Asset (ROA) adalah rasio yang mengukur kemampuan perusahaan menghasilkan laba dengan menggunakan total aset (kekayaan) yang dimiliki perusahaan setelah disesuaikan dengan biaya-biaya yang menandai aset tersebut".

Menurut Kasmir (2008:2004), "Return On Equity (ROE) adalah rasio untuk mengukur laba bersih sesudah pajak dengan modal sendiri”.

Net Interest Margin (NIM) adalah perbandingan antara pendapatan bunga bank dikurangi biaya bunga bank yang menjadi beban.

\section{Hipotesis}

a. Di duga Loan to Deposit Ratio (LDR) dapat mempengaruhi tingkat Rentabilitas pada PT Bank Tabungan Negara (Persero) Tbk.

b. Di duga Capital Adequancy Ratio (CAR) dapat mempengaruhi tingkat Rentabilitas pada PT Bank Tabungan Negara (Persero) Tbk. 
c. Di duga Loan to Deposit Ratio (LDR) dan Capital Adequancy Ratio (CAR) secara bersama-sama dapat mempengaruhi tingkat Rentabilitas pada PT Bank Tabungan Negara (Persero) Tbk.

\section{METODE}

\section{Metode Pengumpulan Data}

Teknik pengumpulan data dilakukan dengan cara:

a. Penelitian Kepustakaan (Library Research).

Dalam metode ini dilakukan untuk memperoleh data sekunder yang dijadikan landasan masalah yang akan diteliti dengan memanfaatkan buku-buku yang berkaitan dengan pokok permasalahan yang sedang dibahas.

b. Penelitian Lapangan (Field Research).

Data diperoleh dengan cara:

1. Pengamatan (Observation), yaitu pengamatan secara langsung dilapangan terhadap objek yang sedang dibahas.

2. Wawancara (Interview Technique), yaitu metode yang digunakan untuk memperoleh informasi secara langsung dengan pihak-pihak terkait dengan melakukan tanya jawab.

\section{Metode Analisis Data}

Analisis data yang digunakan:

a. Analisis Kuantitatif

Cara menganalisis data yang dinyatakan dengan angka-angka, serta melakukan perbandingan untuk mengetahui hasil akhit dari permasalahan yang dibahas.

b. Analisis Deskriptif

Metode yang dilakukan dengan cara menganalisis hasil data yang dinyatakan dalam kalimat yang bertujuan menjelaskan hasil penelitian dengan membandingkan teori yang ada pada literatur dengan praktik di lapangan.

\section{PEMBAHASAN}

\section{Analisis Kuantitatif}

\section{a. Loan to Deposit Ratio (LDR)}

Berdasarkan laporan neraca PT Bank Tabungan Negara (Persero) Tbk diperoleh hasil sebagai berikut:

Tabel 1

Hasil Perhitungan Kredit

(dalam jutaan rupiah)

\begin{tabular}{|l|c|c|c|}
\hline \multicolumn{1}{|c|}{ KREDIT (aktiva) } & 2015 & 2014 & 2013 \\
\hline Kredit Konvensional & $92,386,308$ & $75,410,705$ & $59,337,756$ \\
\hline Pembiayaan Syariah & $8,081,083$ & $5,730,058$ & $4,225,928$ \\
\hline Total Kredit & $100,467,391$ & $81,140,763$ & $63,563,684$ \\
\hline
\end{tabular}

Sumber : Data diolah 
Tabel 2

Hasil Perhitungan Dana Pihak Ketiga

(dalam jutaan rupiah)

\begin{tabular}{|l|c|c|c|}
\hline Dana Pihak Ketiga (pasiva) & 2015 & 2014 & 2013 \\
\hline Giro & $19,116,196$ & $13,271,227$ & $13,149,587$ \\
\hline Tabungan & $24,237,893$ & $21,540,425$ & $14,815,913$ \\
\hline Deposito & $52,853,533$ & $45,856,331$ & $34,004,515$ \\
\hline Total Dana Pihak Ketiga & $96,207,622$ & $80,667,983$ & $61,970,015$ \\
\hline
\end{tabular}

Sumber : Data diolah

$$
\mathrm{LDR}=\frac{\text { Kredit }}{\text { Dana Pihak Ketiga }} \times 100 \%
$$

Tahun $2013=\frac{63 \cdot 563.684}{61 \cdot 970.015} \times 100 \%=102,56 \%$

Tahun $2014=\frac{81.410 .763}{80.667 .983} \times 100 \%=100,90 \%$

Tahun $2015=\frac{100.467 .391}{96.207 .622} \times 100 \%=104,42 \%$

Tabel3

Hasil Perhitungan LDR

(dalam jutaan rupiah)

\begin{tabular}{|c|c|c|c|}
\hline Tahun & Kredit & Dana Pihak Ketiga & LDR \\
\hline 2013 & 63.563 .684 & 61.970 .015 & $102,56 \%$ \\
\hline 2014 & 81.410 .763 & 80.667 .983 & $100,90 \%$ \\
\hline 2015 & 100.467 .391 & 96.207 .622 & $104,42 \%$ \\
\hline
\end{tabular}

Sumber : Data diolah

Jadi, dapat disimpulkan bahwa terjadi penurunan LDR pada tahun 2014 sebesar 1,66\%, karena peningkatan jumlah simpanan sebagai sumber pembiayaan yang lebih tinggi dari peningkatan kredit sebagai aset. Sedangkan di tahun 2015 terjadi peningkatan kembali sebesar $3,52 \%$ yang disebabkan oleh peningkatan kredit sebagai aset yang lebih tinggi dari peningkatan simpanan.

\section{b. Capital Adequancy Ratio (CAR)}

Berdasarkan perhitungan KPMM PT Bank Tabungan Negara (Persero) Tbk diperoleh hasil sebagai berikut:

Tabel 4

Hasil Perhitungan Modal Minimum

(dalam jutaan rupiah)

\begin{tabular}{|c|c|r|c|c|}
\hline I. & $\begin{array}{c}\text { KOMPONEN MODAL } \\
\text { (COMPONENTS) }\end{array}$ & $\mathbf{2 0 1 5}$ & $\mathbf{2 0 1 4}$ & $\mathbf{2 0 1 3}$ \\
\hline A. & Modal Inti (Core Capital) & $\begin{array}{r}10,099,69 \\
2\end{array}$ & $9,038,283$ & $6,584,012$ \\
\hline
\end{tabular}




\begin{tabular}{|c|c|c|c|c|}
\hline B. & $\begin{array}{l}\text { Modal Pelengkap } \\
\text { (Suplementary Capital) }\end{array}$ & 724,630 & 582,272 & 511,747 \\
\hline C. & $\begin{array}{l}\text { Faktor Pengurang Modal Inti } \\
\text { dan Modal Pelengkap }\end{array}$ & 247,393 & 187,393 & 127,393 \\
\hline $\mathrm{D}$ & $\begin{array}{l}\text { Modal Pelengkap Tambahan } \\
\text { Yang Memenuhi Persyaratan } \\
\text { (Tier 3) (Additional } \\
\text { Supplementary Capital (Tier } \\
\text { 3)) }\end{array}$ & - & - & - \\
\hline $\mathrm{E}$ & $\begin{array}{l}\text { Modal Pelengkap Tambahan } \\
\text { yang Dialokasikan untuk } \\
\text { Mengantisipasi Risiko pasar } \\
\text { (Additional Supplementary } \\
\text { Capital which is allocated to } \\
\text { anticipate Market Risk) }\end{array}$ & - & - & - \\
\hline II. & $(A+B-C))$ & $\begin{array}{r}10,576,92 \\
9\end{array}$ & $9,433,162$ & $6,968,366$ \\
\hline III. & $(\mathrm{A}+\mathrm{B}-\mathrm{C}+\mathrm{E})$ & $\begin{array}{r}10,576,92 \\
9\end{array}$ & $9,433,162$ & $6,968,366$ \\
\hline IV. & $\begin{array}{l}\text { (ATMR) UNTUK RISIKO } \\
\text { KREDIT (RISK } \\
\text { WEIGHTED ASSET } \\
(\text { RWA) FOR CREDIT } \\
\text { RISK) } \\
\end{array}$ & $\begin{array}{r}57,970,37 \\
7\end{array}$ & $46,581,762$ & $40,939,774$ \\
\hline V. & $\begin{array}{l}\text { (ATMR) UNTUK RISIKO } \\
\text { OPERASIONAL (RISK } \\
\text { WEIGHTED ASSET } \\
(\text { RWA) FOR } \\
\text { OPERATIONAL RISK) } \\
\end{array}$ & $8,229,190$ & $6,557,227$ & $5,283,745$ \\
\hline VI. & $\begin{array}{l}\text { (ATMR) UNTUK RISIKO } \\
\text { PASAR (RISK } \\
\text { WEIGHTED ASSET } \\
(\text { RWA) FOR MARKET } \\
\text { RISK) }\end{array}$ & 283,944 & 182,400 & 149,515 \\
\hline
\end{tabular}

$$
\mathrm{CAR}=\frac{\text { Modal }}{\mathrm{ATMR}} \times 100 \%
$$

Tahun $2011=\frac{6.968 .366}{46.373 .034} \times 100 \%=15,03 \%$

Tahun $2012=\frac{9.433 .162}{53.321 .389} \times 100 \%=17,69 \%$

Tahun $2013=\frac{10.576 .929}{66.483 .511} \times 100 \%=15,62 \%$ 
Tabel 5

Hasil Perhitungan CAR

(dalam jutaan rupiah)

\begin{tabular}{|c|c|c|c|}
\hline Tahun & Modal Bank & ATMR & CAR \\
\hline 2013 & 6.968 .366 & 46.373 .034 & $15,03 \%$ \\
\hline 2014 & 9.433 .162 & 53.321 .389 & $17,69 \%$ \\
\hline 2015 & 10.576 .929 & 66.483 .511 & $15,62 \%$ \\
\hline
\end{tabular}

Sumber : Data diolah

Jadi, pada tahun 2014 terjadi peningkatan CAR sebesar 2,66\% yang disebabkan pada akhir tahun 2014 modal bank mengalami peningkatan akibat adanya penambahan modal. Sedangkan di tahun 2015 terjadi penurunan kembali sejalan dengan menurunnya aktivitas penambahan modal bank yang hanya berasal dari eksekusi opsi saham dan peningkatan laba bersih, sementara aset produktif bertambah signifikan yang didukung dengan peningkatan liabilitas simpanan dari nasabah.

\section{c. Return On Asset (ROA)}

Berdasarkan laporan neraca dan laporan laba rugi PT Bank Tabungan Negara (Persero) Tbk diperoleh hasil sebagai berikut:

Tabel 6

Hasil Perhitungan Laba Rugi (dalam jutaan rupiah)

\begin{tabular}{|l|c|c|c|}
\hline Tahun & $\mathbf{2 0 1 5}$ & $\mathbf{2 0 1 4}$ & $\mathbf{2 0 1 3}$ \\
\hline Laba Sebelum Pajak & $2,140,771$ & $1,863,202$ & $1,522,260$ \\
\hline
\end{tabular}

Tabel 7

Hasil Perhitungan Neraca

(dalam jutaan rupiah)

\begin{tabular}{|l|c|c|r|c|}
\hline Tahun & $\mathbf{2 0 1 5}$ & $\mathbf{2 0 1 4}$ & $\mathbf{2 0 1 3}$ & $\mathbf{2 0 1 2}$ \\
\hline TOTAL & & & $89,121,45$ & \\
ASET & $131,169,730$ & $111,748,593$ & 9 & $68,385,539$ \\
\hline
\end{tabular}

$$
\mathrm{ROA}=\frac{\text { Laba Sebelum Pajak }}{\text { Rata }- \text { rata Total Aset }} \times 100 \%
$$

Tahun $2013=\frac{1.522 .260}{78.753 .539} \times 100 \%=1,93 \%$

Tahun $2014=\frac{1.863 .202}{100.435 .026} \times 100 \%=1,85 \%$

Tahun $2015=\frac{2 \cdot 140.771}{121.459 .161,5} \times 100 \%=1,76 \%$ 
Tabel 8

Hasil Perhitungan Neraca

(dalam jutaan rupiah)

\begin{tabular}{|c|c|c|c|}
\hline Tahun & Laba Sebelum Pajak & Total Aset & ROA \\
\hline 2013 & $1,522,260$ & $78,753,593$ & $1,93 \%$ \\
\hline 2014 & $1,863,202$ & $100,435,026$ & $1,85 \%$ \\
\hline 2015 & $2,140,771$ & $121,459,161,5$ & $1,76 \%$ \\
\hline
\end{tabular}

Sumber : Data diolah

Dapat dilihat bahwa terjadi penurunan tidak signifikan di tahun 2014 sebesar $0,08 \%$ dan mengalami penurunan kembali sebesar $0,09 \%$ ini terjadi karena adanya peningkatan laba bersih bank yang diikuti juga peningkatan secara signifikan aset yang ada pada Bank BTN.

\section{d. Return On Equity (ROE)}

Berdasarkan laporan neraca dan laporan laba rugi PT Bank Tabungan Negara (Persero) Tbk diperoleh hasil sebagai berikut:

Tabel 9

Hasil Perhitungan Laba Rugi

(dalam jutaan rupiah)

\begin{tabular}{|l|c|c|c|}
\hline Tahun & $\mathbf{2 0 1 3}$ & $\mathbf{2 0 1 2}$ & $\mathbf{2 0 1 1}$ \\
\hline Laba Setelah Pajak & $1,562,161$ & $1,363,962$ & $1,118,661$ \\
\hline
\end{tabular}

Sumber : Data diolah

Tabel 10

Hasil Perhitungan Neraca

(dalam jutaan rupiah)

\begin{tabular}{|l|r|c|c|c|}
\hline Tahun & \multicolumn{1}{|c|}{$\mathbf{2 0 1 3}$} & $\mathbf{2 0 1 2}$ & $\mathbf{2 0 1 1}$ & $\mathbf{2 0 1 0}$ \\
\hline TOTAL & $11,556,75$ & & & \\
EKUITAS & 3 & $10,278,871$ & $7,321,643$ & $6,447,278$ \\
\hline
\end{tabular}

Sumber : Data diolah

$$
\mathrm{ROE}=\frac{\text { Laba Setelah Pajak }}{\text { Rata }- \text { rata Total Ekuitas }} \times 100 \%
$$

Tahun $2013=\frac{1.118 .661}{6.884 .460,5} \times 100 \%=16,24 \%$

Tahun $2014=\frac{1.363 .962}{8.800 .257} \times 100 \%=15,49 \%$

Tahun $2015=\frac{1.562 .161}{10.916 .812} \times 100 \%=14,37 \%$

Tabel 11

Hasil Perhitungan ROE

(dalam jutaan rupiah)

\begin{tabular}{|c|c|c|c|}
\hline Tahun & Laba setelah Pajak & Total Equity & ROE \\
\hline 2013 & $1,118,661$ & $6,884,460,5$ & $16,24 \%$ \\
\hline 2014 & $1,363,962$ & $8,800,257$ & $15,49 \%$ \\
\hline 2015 & $1,562,161$ & $10,916,812$ & $14,37 \%$ \\
\hline
\end{tabular}

Sumber : Data diolah 
Terjadi penurunan ROE selama 3 tahun terakhir yakni sebesar 0,75\% pada tahun 2014 dan sebesar $0,12 \%$ pada tahun 2015 , dikarenakan adanya pertumbuhan modal saham pada bank BTN.

\section{e. Net Interest Margin (NIM)}

Berdasarkan laporan neraca dan laporan laba rugi PT Bank Tabungan Negara (Persero) Tbk diperoleh hasil sebagai berikut:

Tabel 12

Hasil Perhitungan Laba Rugi

(dalam jutaan rupiah)

\begin{tabular}{|c|c|c|c|}
\hline Tahun & $\mathbf{2 0 1 5}$ & $\mathbf{2 0 1 4}$ & $\mathbf{2 0 1 3}$ \\
\hline Pendapatan bunga bersih & $5,653,323$ & $4,726,819$ & $3,785,873$ \\
\hline
\end{tabular}

Tabel 13

Hasil Perhitungan Neraca

(dalam jutaan rupiah)

\begin{tabular}{|l|c|c|r|c|}
\hline Tahun & $\mathbf{2 0 1 5}$ & $\mathbf{2 0 1 4}$ & $\mathbf{2 0 1 3}$ & $\mathbf{2 0 1 2}$ \\
\hline TOTAL AKTIVA & & & $71,926,03$ & \\
PRODUKTIF & $113,542,599$ & $90,671,001$ & 6 & $60,124,799$ \\
\hline
\end{tabular}

$$
\mathrm{NIM}=\frac{\text { Pendapatan Bunga Bersih }}{\text { Rata }- \text { rata Aktiva Produktif }} \times 100 \%
$$

Tahun $2013=\frac{3.785 .873}{66.025 .417,5} \times 100 \%=5,73 \%$

Tahun $2014=\frac{4.726 .819}{81,298.518,5} \times 100 \%=5,81 \%$

Tahun $2015=\frac{5.653 .323}{102.106 .800} \times 100 \%=5,53 \%$

Tabel 14

Hasil Perhitungan NIM

(dalam jutaan rupiah)

\begin{tabular}{|c|c|c|c|}
\hline Tahun & Pendapatan Bunga bersih & Aktiva produktif & NIM \\
\hline 2013 & $3,785,873$ & $66,025,417,5$ & $5,73 \%$ \\
\hline 2014 & $4,726,819$ & $81,298,518,5$ & $5,81 \%$ \\
\hline 2015 & $5,653,323$ & $102,106,800$ & $5,53 \%$ \\
\hline
\end{tabular}

Sumber : Data diolah

Terjadi peningakatan pada tahun 2014 sebesar $0,07 \%$, disebabkan oleh pertumbuhan aset yang signifikan pada tahun 2014 sehingga bank mengalami kenaikan portofolio yang memuaskan yang merupakan dasar perhitungan pendapatan bunga oleh bank. Dan terjadi penurunan kembali pada tahun 2015 sebesar 0,29\% penurunan ini disebabkan peningkatan suku bunga simpanan pada kuartal terakhir ditahun 2015 yang mempengaruhi beban bunga selaku beban pokok pendapatan. 


\section{f. Pengaruh LDR dan CAR terhadap Rentabilitas}

Tabel 15

Hasil Perhitungan LDR,CAR,NPL,ROA,ROE,NIM

\begin{tabular}{|c|c|c|c|c|c|c|}
\hline Tahun & LDR & CAR & NPL & ROA & ROE & NIM \\
\hline 2013 & $102,56 \%$ & $15,03 \%$ & $2,23 \%$ & $1,93 \%$ & $16,24 \%$ & $5,73 \%$ \\
\hline 2014 & $100,90 \%$ & $17,69 \%$ & $3,12 \%$ & $1,85 \%$ & $15,49 \%$ & $5,81 \%$ \\
\hline 2015 & $104,42 \%$ & $15,62 \%$ & $3,04 \%$ & $1,76 \%$ & $14,37 \%$ & $5,53 \%$ \\
\hline
\end{tabular}

1. Semakin tinggi LDR maka berpengaruh terhadap laba perusahaan yang juga mengalami peningkatan (dengan asumsi bank tersebut mampu menyalurkan kredit dengan efektif, sehingga jumlah kredit bermasalah (macet) akan kecil). Kredit yang diberikan adalah kredit yang diberikan bank yang sudah ditarik atau dicairkan bank. Kredit yang diberikan tidak termasuk kredit kepada bank lain.

2. CAR sangat berpengaruh terhadap rentabilitas, karena CAR yang tinggi membuktikan bahwa suatu perusahaan terutama perbankan mampu membiayai operasi bank tersebut dan keadaan menguntungkan tersebut dapat memberikan kontribusi yang besar bagi rentabilitas. Dan disisi lain dengan CAR yang tinggi berarti bank mampu menutupi risiko kerugian yang mungkin timbul dari penanaman aset yang mengandung risiko.

3. LDR dan CAR berpengaruh secara bersama-sama terhadap rentabilitas. Karena jika LDR dan CAR mengalami kenaikan maka rentabilitas meningkat. Hal ini dipengaruhi oleh kas, piutang yang berupa kredit, persediaan, modal dan biaya-biaya. Namun LDR pada Bank BTN menunjukan kecenderungan yang meningkat, sedangkan CAR justru menunjukan penurunan karena pertumbuhan kredit yang lebih tinggi sedangkan modal pada Bank BTN memiliki kecenderungan yang relatif stabil.

\section{Analisis Deskriptif}

PT Bank Tabungan Negara (Persero) Tbk merupakan financial institution milik pemerintah yang tergabung dalam Badan Usaha Milik Negara (BUMN). Bank ini merupakan satu-satunya bank umum yang fokus bisnisnya adalah pembiayaan perumahan baik subsidi maupun non subsidi. Sesuai dengan visi bank BTN itu sendiri yakni menjadi bank terkemuka dalam pembiayaan perumahan. Laporan keuangan digunakan untuk memberikan gambaran perkembangan atau laporan kemajuan suatu perusahaan secara periodik, yang dilakukan manajeman perusahaan yang bersangkutan, yang ditunjukan para pemakai disamping untuk manajemen sendiri.

Untuk mengetahui posisi keuangan suatu perusahaan serta hasil-hasil yang dicapai oleh perusahaan tersebut perlu adanya laporan keuangan perusahaan yang bersangkutan. Tujuan analisis ini adalah menganalisis semua angka-angka yang saling berkaitan dalam rangka memecahkan masalah.

Dengan demikian, analisis terhadap pos-pos neraca akan dapat diketahui atau akan dapat diperoleh gambaran mengenai posisi keuangan sedangkan analisis terhadap laporan laba rugi akan memberikan gambaran tentang hasil atau perkembangan usaha pada PTBank Tabungan Negara (Persero) Tbk.

Neraca bank adalah laporan keuangan yang diterbitkan setiap hari kerja oleh satuan akunting. Laporan tersebut menunjukkan posisi saldo serta mutasi-mutasi dari rekening yang dikelola oleh satuan kerja akunting yang bersangkutan. 
Aktiva bank pada umumnya terdiri atas alat-alat likuid, aktiva produktif dan aktiva tidak produktif. Sisi pasiva menggambarkan kewajiban bank yang berupa klaim pihak ketiga atau pihak lainnya atas kekayaan bank yang dinyatakan dalam bentuk rekening giro, deposito berjangka, tabungan dan instrument kewajiban lainnya serta ekuitasnya yang menggambarkan nilai buku pemilik saham bank.

\section{PENUTUP}

Berdasarkan hasil analisis yang telah penulis lakukan maka dapat dibuat beberapa kesimpulan sebagai berikut:

1. Dilihat dari sisi Likuiditas yakni dengan penghitungan menggunakan rasio Loan to Deposit Ratio pada Bank BTN dapat dikatakan melebihi rata-rata ketetapan pemerintah, walaupun terjadi penurunan pada tahun 2014 sebesar 1,66\% dikarenakan peningkatan sumber pembiayaan yang lebih tinggi daripada peningkatan kredit, sehingga terjadi penurunan rasio. Dan terjadi peningkatan kembali pada tahun 2015 sebesar 3,52\%, karena peningkatan kredit sebagai aset yang lebih tinggi dari peningkatan simpanan sebagai sumber pendanaan. Tapi semakin tinggi LDR maka laba perusahaan semakin meningkat dengan asumsi bank mampu memberikan kredit secara efektif agar tidak terjadi kredit macet.

2. Dilihat dari sisi solvabilitas, yakni dengan penghitungan Capital Adequancy Ratio (CAR). Di tahun 2014 terjadi peningkatan sebesar 2,66\% lebih tinggi dari sebelumnya dikarenakan adanya penambahan modal yang berasal dari pelaksanaan Right Issue Bank. Dan ditahun berikutnya yakni tahun 2015 terjadi penurunan kembali sebesar $2,07 \%$ karena menurunnya aktivitas penambahan modal yang hanya berasal dari eksekusi saham dan peningkatan laba bersih. Jadi, CAR yang tinggi berarti bank mampu membiayai operasi bank dan keadaan tersebut mampu memberikan kontribusi yang cukup besar bagi rentabilitas.

3. Loan to Deposit Ratio (LDR) pada bank BTN menunjukan kecenderungan yang meningkat, sedangkan Capital Adequancy Ratio (CAR) justru menunjukan kecenderungan yang menurun karena pertumbuhan kredit yang lebih tinggi akibat ekspansi kredit yang dilakukan BTN secara besar-besaran sedangkan pertumbuhan modal BTN stabil. Kondisi seperti ini yang pada akhirnya menyebabkan apabila terjadi kenaikan CAR maka LDR akan mengalami penurunan.Namun disisi lain LDR dan CAR berpengaruh secara bersama-sama terhadap rentabilitas. Karena jika LDR dan CAR mengalami kenaikan maka rentabilitas meningkat. Hal ini dipengaruhi oleh kas, piutang yang berupa kredit, persediaan, modal dan biaya-biaya.

Berdasarkan kesimpulan yang telah diuraikan, maka penulis mencoba memberikan saran sebagai bahan masukan dan pertimbangan, yaitu sebagai berikut:

1. Karena rasio likuiditas pada Bank BTN yang fluktuatif melebihi ketetapan yang diberikan oleh Bank Indonesia, dengan alasan kredit dan simpanan yang selalu meningkat tiap tahunnya. Bank harus tetap menjaga stabilitas antara kredit dan simpanan, agar bank tetap dalam posisi likuid. Oleh karena itu pada saat bank memberikan kredit harus menerapkan prisip kehati-hatian agar tidak terjadi penangguhan dalam pembayaran kreditnya atau tidak terjadi kredit macet yang akan membuat kondisi keuangan bank tidak stabil.

2. Bagi perusahaan diharapkan selalu menjaga tingkat modalnya, sehingga akan meningkatkan kinerja keuangan bank tersebut. Dengan melihat variable CAR diharapkan bank mampu menyediakan dana untuk keperluan pengembangan usaha 
serta menampung kemungkinan risiko kerugian yang diakibatkan operasional bank.

3. Karena rasio LDR berpengaruh terhadap CAR sebaiknya bank dapat menentukan jumlah modal bank sehingga dapat memprediksi jumlah kredit yang akan disalurkan kepada masyarakat.

\section{Daftar Pustaka}

Internet,http // www,bi,go,id

Kasmir,Bank \& Lembaga Keua ngan Lain,Penerbit Raja Grafindo Persada,Edisi 6,Jakarta,2002.

Sigit Triandaru,A.Totok Budi Santoso, bank \& Lembaga Keuangan Lain, Edisi 2, Penerbit

Salemba Empat,Jakarta,2006.

Tanpa nama,2015," Laporan Keuangan Publikasi Bank".http// www,bi,go,id / publikasi laporan Keuangan bank umum:

Y.Sri Susilo,Sigit Triandaru, A.Totok Budi Santoso,Bank \& Lembaga Keuangan Lain, Penerbit Salemba Empat, Jakarta,2000. 